\title{
Distribution Network Reconfiguration and its Algorithm
}

\author{
Huixia Sun ${ }^{1, a}$, Yueguang $\mathrm{Li}^{2, \mathrm{~b}}$ \\ ${ }^{1}$ Gansu Normal University for Nationalities, Hezuo, gansu, 747000, China \\ ${ }^{2}$ Gansu Normal University for Nationalities, Hezuo, gansu, 747000, China \\ aYueguangli7@163.com, bYueguangli7@sohu.com
}

Keywords: Plant Growth Simulation Algorithm; Network reconfiguration; Distribution; heuristics

\begin{abstract}
In this paper, a plant growth simulation algorithm was used to solve distribution network reconfiguration. The effectiveness of the proposed method has been tested and verified on IEEE 33 bus distribution system, the experimental results show that the Plant Growth Simulation Algorithm has better feasibility and validity for solving distribution network reconfiguration.
\end{abstract}

\section{Introduction}

Distribution network reconfiguration is defined as altering the topological structures of distribution feeders by changing the open/closed states of the sectionalizing and tie switches. It can not only alter the load level of the feeders, but also improve the voltage profile along the feeders and reduce the loss reduction of the whole system. Thus, reconfiguration is vital to the reliability and security of the distribution system. Subject to operational and multi-objective constraints, the reconfiguration problem is a large scale nonlinear combinatorial optimization problem. The number of the optimization variables, switches is huge, which will lead to combination explosion. If there are $\alpha$ switches in the system, $\alpha^{2}$ possible solution will exit. Some of these solutions will cause isolation of part of a feeder or loop systems, and other solutions violate the operational constraints. Changing the states of the switches will alter the operating conditions of the overall system.

So far, researchers have done a lot of work in distribution network reconfiguration and many algorithms have been proposed. Generally speaking, there are two typical kinds of solutions: the first one is heuristic search method ${ }^{[1]}$, which is easy understanding simple and fast. But the methods may lead to local optimal solutions. The second one is humane intelligence algorithm, such as Genetic Algorithm (GA) ${ }^{[2]}$ 、Artificial Neural Networks (ANN) ${ }^{[3]}$, Tabu Search algorithm(TS) ${ }^{[4]}$, which is more likely to obtain the global optimal solution.

\section{The plant growth simulation algorithm}

Plant growth simulation algorithm (PGSA) is an evolutionary computation technique through simulating the growth processes in plants, which is based on the principles of plant phototropism growth ${ }^{[5]}$. The algorithm has a good prospect in the application due to requiring a simple on the parameters. It has gradually been applied in the field of engineering by many scholars ${ }^{[6]}$. PGSA sets up several basic conception: root trunk , branch 、 growth point and light source. The root of a plant expresses initial solution; the trunk and branch correspond to the search domain of possible solutions; the selected growth point expresses the base of next searching process and the light source represents the global optimal solution. The key point of PGSA is selecting one growth point to erupt into branch, and ensuring the branch growing toward the light source.

Plants can be viewed as a system, which composes of a large number of branches and nodes. It must be as soon as possible to strive for breeding more branches and leaves for earning more surface areas, which can obtain the greatest possible sunlight. The form of grammar that simulates the plant description analysis and development had been established since linguistics was introduced into the biological, which based on a simple rewrite rules and branching rules, this is called L-system. Formal description of plant growth can be carried out as the following: 
1. The section of the site grow new branches which first emerged in a number of stems is called the growth node.

2. Most of the new branches have grown updated branches, and the process repeated on the old and new branches.

3. Different branches in the tree have similarities with each other, and the entire plant has self-similar structure.

The Branching model of plant growth is improved according to L-system combined with computer graphics and fractal theory, the plant, as the form of plant growth characteristics, can be described as follow: Supposed branches of plant growth occurred in the two-dimensional plane, Each branch growing in units length every time, or rotating a certain angle $\alpha$, Starting from the node of trunk or branches, The growth process were repeated through rewriting the rules of branches of plant growth in the two dimensional plane.

It was proved by biological experiments that a new branch that is able to grow depends on its morphactin concentration when the plant has more than one node. The node which has larger value of morpheme concentration has more growth opportunities than the smaller one, morphactin concentration are not pre-assigned to the nodes, but formed according to their location information which we call that plant showed the feature of plant's Phototropism. After the node has been formed, morphactin concentration will be readjusted according to changing in the environment of a new growth node else.

We could describe the characteristics of plant growth in term of the mathematical view basis on plant growth analysis of the above. Suppose the length of tree trunk is T, the length of branch is L, there are $\mathrm{W}$ growing nodes $S_{T}=\left(S_{T 1}, S_{T 2}, \ldots, S_{T W}\right)$ in the trunk, morphactin concentration of those nodes is $P_{T}=\left(P_{T 1}, P_{T 2}, \ldots, P_{T W}\right)$ respectively. There are $q$ growth nodes $S_{T}=\left(S_{T 1}, S_{T 2}, \ldots, S_{T q}\right)$ in the branch. Morphactin concentration of those nodes is $P_{T}=\left(P_{T 1}, P_{T 2}, \ldots, P q\right)$ respectively. The morphactin concentration which grown in the trunk and branch is calculated as follows:

$$
P_{T i}=f\left(x_{0}\right)-f\left(S_{T i}\right) / \sum_{i}^{W}\left(f\left(x_{0}\right)-f\left(S_{T i}\right)\right)+\sum_{j}^{q}\left(f\left(x_{0}\right)-f\left(x_{T q}\right)\right)
$$

Where $x_{0}$ represents the root of plant (the initial node), $f(*)$ is the information function of the node in the environment, The smaller value of the function as possible shows the better environment where the node located, it will help to grow new branch.

From formula (7), the value of morphactin concentration in every node depends on relative position of the relative to the initial root and the location of the environmental information, the mechanism consistent with the formation of the morphactin concentration in the plant cell. We can deduced from formula (7) as follows:

$$
\sum_{i=1}^{T} \sum_{j=1}^{q}\left(P_{T i}+P_{T j}\right)=1
$$

We can produce random number in the interval $[0,1]$. The random number must fall within one of the state space $\left(P_{1}, P_{2}, \ldots, P_{T+q}\right)$, where the corresponding node will have a prior right to grow new branch. A simple example of morphactin concentration state space displays in the fig. 1.The value of morphactin concentration in all nodes will change after the new branch has grown up. Computation formula of the value of morphactin concentration in other nodes will add the relevant node on the new branch, and remove the grown node, which basis on formula (7). The process will be repeated until there is no new branches growing.

In this paper, independent loops are adopted as decision variables. And the temporary closed switches are not numbered while forming the possible solution sets of decision variables ${ }^{[7]}$. Take IEEE 33 bus distribution system in Fig. 1 as an example. The define decision variables are $\left[\mathrm{x}_{1}, \mathrm{x}_{2}\right.$, $\mathrm{x}_{3}, \mathrm{x}_{4}, \mathrm{x}_{5}$, which mean switches opened in Loop 1, Loop 2,.., Loop 5.For example, there are switches $\mathrm{S}_{18}, \mathrm{~S}_{19}, \mathrm{~S}_{20}, \mathrm{~S}_{2}, \mathrm{~S}_{3}, \mathrm{~S}_{4}, \mathrm{~S}_{5}, \mathrm{~S}_{6}, \mathrm{~S}_{7}, \mathrm{~S}_{33}$ in Loop 1, then the possible solution set of $x_{1}$ is $[18,19,20,2,3,4,5,6,7,33]$. When $x_{1}$ equals to 18 , that means all switches in Loop 1 are closed 
except switchS ${ }_{18}$. The traversal search method is not adopted in the proposed method, so we do not need to renumber the switches as literature [7].

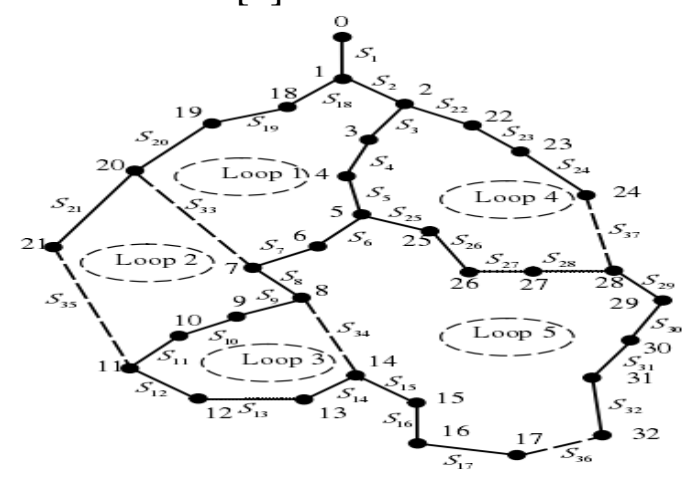

Fig1. The 33 bus system with loop number

\section{The analysis of simulation}

Run environment of algorithm is MATLAB (R2010b) under Win7 operating system. Parameters: $f_{\min }=0, f_{\max =1}, \alpha=\gamma=0.9$, the lower bound of speed $v_{\min =-0.5}$, the upper bound of speed $v_{\max }$ $=0.5$, the initial velocity $\mathrm{v}=0$, the initial frequency $\mathrm{f}=0$, the initial loudness $\mathrm{A}=0.5$ and initial pulse frequency $\mathrm{R}=0.2$.

The IEEE 33 bus distribution system [7] is used to demonstrate the validity and effectiveness of the proposed algorithm. The network consists of 33 buses and 5 tie lines, as shown in Fig.1. The original open switches are S33, S34, S35, S36 and S37, and the corresponding power losses is 202.7 $\mathrm{kW}$. To verify the proposed algorithm can get global optimizations under different initial solutions, this paper adds another initial solution: open switches areS33 , S34 , S35 , S31 , S37 and the power losses is $218.7 \mathrm{~kW}$.

Heuristic search methods may lead to local optimal solutions, as shown in Table 1. Under initial state I, only converges to the global optimal solutions. But, under initial state II, converges to a local optimal solution. Ref. The proposed algorithm converges to the global optimal solution under both initial states. And the allowable consecutive iterative number Nmax is assumed to be 4 . The convergence characteristics of the proposed algorithm in test systems is shown is Fig. 2. Furthermore, the proposed algorithm significantly reduces the computational requirement of PGSA. In each iterative step, PGSA will generate $46(9+6+6+10+15=46)$, the sum of sectionalizing switches of the five loops) growth points, which means power flow, objective function evaluation and morphactin concentration calculation are required to run 46 times. But, in the proposed algorithm the number of growth points generated in each iterative step is reduced to 5 .

Table 1 The test results

\begin{tabular}{|c|c|c|c|c|c|c|c|c|}
\hline \multirow{2}{*}{\multicolumn{2}{|c|}{$\begin{array}{c}\text { Initial Open } \\
\text { Switches }\end{array}$}} & \multirow{2}{*}{$\begin{array}{l}\text { Initial } \\
\text { Power } \\
\text { Losses }\end{array}$} & \multicolumn{2}{|c|}{ [2] } & \multicolumn{2}{|c|}{ [3] } & \multicolumn{2}{|c|}{$\begin{array}{l}\text { The Proposed } \\
\text { Algorithm }\end{array}$} \\
\hline & & & $\begin{array}{l}\text { Last Open } \\
\text { Switches }\end{array}$ & $\begin{array}{l}\text { Last } \\
\text { Power } \\
\text { Losses } \\
\end{array}$ & $\begin{array}{l}\text { Last Open } \\
\text { Switches }\end{array}$ & $\begin{array}{l}\text { Last } \\
\text { Power } \\
\text { Losses }\end{array}$ & $\begin{array}{l}\text { Last Open } \\
\text { Switches }\end{array}$ & $\begin{array}{l}\text { Last } \\
\text { Power } \\
\text { Losses }\end{array}$ \\
\hline I & $\begin{array}{c}\mathrm{S}_{33}, \mathrm{~S}_{34}, \\
\mathrm{~S}_{35}, \mathrm{~S}_{36}, \mathrm{~S}_{37}\end{array}$ & $202.7 \mathrm{~kW}$ & $\begin{array}{c}\mathrm{S}_{7}, \mathrm{~S}_{9}, \\
\mathrm{~S}_{14}, \mathrm{~S}_{28}, \mathrm{~S}_{36}\end{array}$ & $\begin{array}{c}141.9 \\
\mathrm{~kW}\end{array}$ & $\begin{array}{c}\mathrm{S}_{7}, \mathrm{~S}_{9}, \\
\mathrm{~S}_{14}, \mathrm{~S}_{37}, \mathrm{~S}_{32}\end{array}$ & $\begin{array}{c}139.5 \\
\mathrm{~kW}\end{array}$ & $\begin{array}{c}\mathrm{S}_{7}, \mathrm{~S}_{9}, \\
\mathrm{~S}_{14}, \mathrm{~S}_{37}, \mathrm{~S}_{32}\end{array}$ & $\begin{array}{c}138.5 \\
\mathrm{~kW}\end{array}$ \\
\hline II & $\begin{array}{c}\mathrm{S}_{33}, \mathrm{~S}_{34}, \\
\mathrm{~S}_{35}, \mathrm{~S}_{31}, \mathrm{~S}_{37}\end{array}$ & $202.7 \mathrm{~kW}$ & $\begin{array}{c}\mathrm{S}_{7}, \mathrm{~S}_{9}, \\
\mathrm{~S}_{14}, \mathrm{~S}_{37}, \mathrm{~S}_{32}\end{array}$ & $\begin{array}{c}139.5 \\
\mathrm{~kW}\end{array}$ & $\begin{array}{c}\mathrm{S}_{7}, \mathrm{~S}_{9}, \\
\mathrm{~S}_{14}, \mathrm{~S}_{37}, \mathrm{~S}_{31}\end{array}$ & $\begin{array}{c}142.6 \\
\mathrm{~kW}\end{array}$ & $\begin{array}{c}\mathrm{S}_{7}, \mathrm{~S}_{9}, \\
\mathrm{~S}_{14}, \mathrm{~S}_{37}, \mathrm{~S}_{32}\end{array}$ & $\begin{array}{c}138.5 \\
\mathrm{~kW}\end{array}$ \\
\hline
\end{tabular}




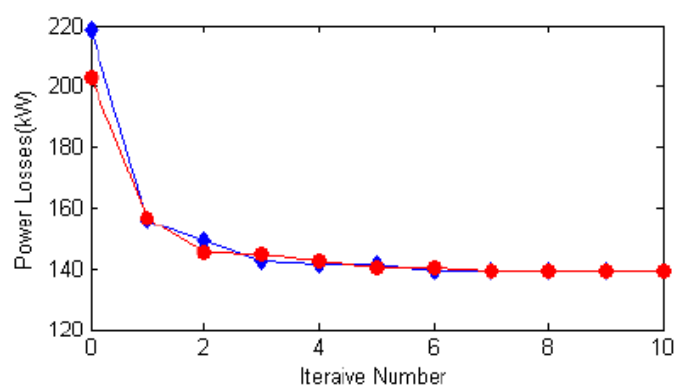

Fig2. Convergence curve of proposed method

\section{Conclusions}

This paper proposes an improved plant growth simulation algorithm, the improved algorithm is applied to solve distribution network reconfiguration, the performance has been improved obviously. Experiments show that: The algorithm is effective and robust, it is feasible and effective for solving distribution network reconfiguration.

\section{References}

[1] M. E. Baran, F. F. Wu, "Network reconfiguration in distribution systems for loss reduction and load balancing,” IEEE Trans. on Power Delivery, 1989, 4:1401-1407.

[2] K. Nara, A. Shiose, M. Kitagawa, T. Ishihara, "Implementation of Genetic Algorithm for Distribution Systems Loss Minimum Reconfiguration,” IEEE Trans on Power Systems, 1992, 8(7): 1044-1051.

[3] Kim Hoyong, Ko Yunseok, Jung Kyung-Hee, “Artificial Neural-Network based feeder reconfiguration for loss reduction in distribution systems," IEEE Trans. on Power Delivery, 1993, 8:1356-1366.

[4] K. Nara, Y. Mishima, A. Giyo, T. Ito, H. Kaneda, "Loss minimum re-configuration of distribution system by tabu search," Transimission and Distribution Conference and Exhibition, 2002,10 (1): 232-236.

[5] Li T, Wang C F, et al. A global optimization bionics algorithm for solving integer Programming plant growth simulation algorithm[J] .Systems Engineering - Theory \& Practice, 2005, 25(1): 85.

[6] Li T, Wang Z t. Application of plant growth simulation algorithm on solving facility location problem [J]. Systems Engineering - Theory \& Practice, 2008, (12):107-115

[7] C. Wang, H. Z. Cheng, "Optimization of network configuration in large distribution systems using plant growth simulation algorithm,” IEEE Trans. on Power Systems, 2008, 2(23): 119-126. 